\title{
Polissacarídeos naturais como abordagem terapêutica experimental no trato gastrointestinal: uma revisão sistemática
}

Natural polysacarides as an experimental therapeutic approach to the gastrointestinal tract: a systematic review

Polisacáridos naturales como enfoque terapéutico experimental del tracto gastrointestinal: una revisión sistemática

Yama Vitoriano Lima

ORCID: https://orcid.org/0000-0002-0802-4221 Instituto de Educação Superior do Vale do Parnaíba, Brasil E-mail: yamavitoriano@ hotmail.com Alcione Barbosa Viana Filho

ORCID: https://orcid.org/0000-0001-5428-3550 Instituto de Educação Superior do Vale do Parnaíba, Brasil E-mail: alci1filho@gmail.com

Marina Santos Mariano

ORCID: https://orcid.org/0000-0002-8040-7972 Instituto de Educação Superior do Vale do Parnaíba, Brasil E-mail: marinasantos.mariano@gmail.com

Thiago de Souza Lopes Araújo

ORCID: https://orcid.org/0000-0001-8543-8498 Instituto de Educação Superior do Vale do Parnaíba, Brasil E-mail: thiago_parnaiba@ hotmail.com

\begin{abstract}
Resumo
O objetivo desse trabalho foi realizar uma análise sistemática da literatura acerca dos principais efeitos dos polissacarideos naturais extraídos de plantas e algas em modelos experimentais de distúrbios gastrointestinais (DGI). Esta revisão se concentra em avanços recentes em estudos experimentais com polissacarídeos naturais no tratamento de doença de refluxo gastroesofágico (DRGE), gastrite, colite e diarreia. Trata-se de uma pesquisa bibliográfica, com abordagem qualitativa, tendo em vista os procedimentos de análise e interpretação dos dados obtidos, realizada através de buscas nas bases de dados: Medical Literature Analysis and Retrievel System Online (Medline), Scientific Electronic Library Online (Scielo) e Biblioteca Nacional de Medicina dos Estados Unidos (PubMed), utilizando os descritores: gum, sulfated polysaccharide, polysaccharide, gastric damage, antidiarrheal, gastroesophageal reflux e colitis em diferentes combinações utilizando o operador booleano "and". Os artigos incluídos no estudo foram somente os que estavam inclusos nas plataformas, sendo considerados artigos, teses e dissertações, incluídos e indexados no período entre 2011 e 2021, que tivessem como metodologia principal estudos experimentais, préclínicos em espectro de atividades in vitro e in vivo sobre os efeitos dos polissacarídeos naturais em modelos de distúrbios gastrointestinais. Os demais artigos que não se enquadravam nesses critérios foram excluídos, chegando a amostra final de 35 trabalhos. Os mecanismos e a efetividade dos polissacarídeos são apresentados e discutidos em detalhes. Em geral, por apresentarem propriedades anti-inflamatória, antioxidante, gastroprotetora e antidiarreica, com boa eficácia e segurança, os estudos sugerem que os polissacarídeos naturais são uma alternativa interessante para o desenvolvimento de terapias inovadoras para DGI.
\end{abstract}

Palavras-chave: Polissacarídeos; Refluxo gastroesofágico; Gastrite; Colite; Diarreia.

\section{Abstract}

The purpose of this study is to conduct a systematic literature review on the main effects of natural polysaccharides extracted from plants and algae in experimental models of gastrointestinal disorders (GID). This review focuses on recent advances in experimental studies with natural polysaccharides for the treatment of gastroesophageal reflux disease (GERD), gastritis, colitis, and diarrhea. This is a bibliographical research based on a qualitative approach, considering the procedures for analyzing and interpreting the data obtained, carried out through searches in the following databases: Medical Literature Analysis and Retrievel System Online (Medline), Scientific Electronic Library Online (Scielo) and the National Library of Medicine of the United States (PubMed), using the descriptors: gum, sulfated polysaccharide, polysaccharide, gastric damage, antidiarrheal, gastroesophageal reflux and colitis in different combinations using the Boolean operator "and". The works inserted in this study were only those available 
in the platforms and classified as articles, theses and dissertations, included and indexed between 2011 and 2021 , which had as their principal methodology experimental and preclinical studies in the spectrum of activities in vitro and in vivo about the effects of natural polysaccharides in models of gastrointestinal disorders. The final sample was composed of 35 papers, as studies that did not fit these criteria were unconsidered. The mechanisms and the effectiveness of polysaccharides are minutely presented and discussed. In general, because of their anti-inflammatory, antioxidant, gastroprotective and antidiarrheal properties, demonstrating satisfactory efficacy and safety, studies suggest that natural polysaccharides are an interesting alternative for the development of innovative therapies for GID.

Keywords: Polysaccharides; Gastroesophageal reflux; Gastritis; Colitis; Diarrhea.

\section{Resumen}

El objetivo de este trabajo fue realizar un análisis sistemático de la literatura sobre los principales efectos de los polisacáridos naturales extraídos de plantas y algas en modelos experimentales de trastornos gastrointestinales (GID). Esta revisión se centra en los avances recientes en estudios experimentales con polisacáridos naturales en el tratamiento de la enfermedad por reflujo gastroesofágico (ERGE), gastritis, colitis y diarrea. Se trata de una investigación bibliográfica, con abordaje cualitativo, considerando los procedimientos de análisis e interpretación de los datos obtenidos, realizados mediante búsquedas en las siguientes bases de datos: Medical Literature Analysis and Retrievel System Online (Medline), Scientific Electronic Library Online (Scielo) y la Biblioteca Nacional de Medicina de los Estados Unidos (PubMed), utilizando los descriptores: chicle, polisacárido sulfatado, polisacárido, daño gástrico, antidiarreico, reflujo gastroesofágico y colitis en diferentes utilizando el operador booleano "e". Los artículos incluidos en el estudio fueron solo aquellos que fueron incluidos en las plataformas, siendo considerados artículos, tesis y disertaciones, incluidos e indexados en el período comprendido entre 2011 y 2021, que tuvieron como metodología los principales estudios experimentales, preclínicos en el espectro de actividades in vitro e in vivo sobre los efectos de polisacáridos naturales en modelos de trastornos gastrointestinales. Se excluyeron los demás artículos que no cumplían con estos criterios, llegando a la muestra final de 35 trabajos. Los mecanismos y la eficacia de los polisacáridos son necesarios y se comentan en detalle. En general, por poseer propiedades antiinflamatorias, antioxidantes, gastroprotectoras y antidiarreica, con buena eficacia y seguridad, estudios avanzados demuestran que los polisacáridos naturales son una alternativa interesante para el desarrollo de terapias innovadoras para la GID.

Palabras clave: Polisacáridos; Reflujo gastroesofágico; Gastritis; Colitis; Diarrea.

\section{Introdução}

Os produtos naturais e seus derivados representam uma fonte inestimável de biomoleculas com propriedades farmacológicas, contribuindo significativamente para a descoberta e screenings de novos medicamentos (Brito, et al., 2014). Como resultado, respondem a nível mundial, por mais de 50\% de todas as drogas de uso clínico (Batista, et al., 2020). Nessa perspectiva, estima-se que a medicina herbal é ainda a fonte mais comum de cuidados de saúde primários, principalmente, nos países em desenvolvimento (El Sayed, et al., 2011).

Os metabolitos secundários extraídos de fontes naturais podem ser subdivididos em diversas classes, incluindo alcalóides, esteróides, terpenoides, flavanoides, isocumarinas, quinonas, fenilpropanóides, ácidos fenólicos, taxol, polissacarídeos e outros (Pamphile, et al., 2017). Os polissacarídeos são polímeros complexos, heterogêneos, de alto peso molecular e carga negativa, formados por unidades repetidas de dissacarídeos, estando presentes em tecidos extracelulares de uma vastidão de organismos vivos, dentre estes, plantas superiores e algas (Batista, et al., 2020). São reconhecidos por suas interações eletrostáticas com proteínas específicas e pelo grande número de atividades biológicas, incluindo propriedades anticoagulantes, antivirais, antitrombóticas, ação antiproliferativa, imunoestimuladora, antitumoral, anti-inflamatória, antinociceptiva, antioxidante, gastroprotetora e antidiarreica (Sousa, et al., 2016).

Nos últimos anos, o interesse pela composição química de plantas e algas marinhas cresceu devido aos seus benefícios para a saúde (Fonseca, 2016). Nas plantas superiores, os polissacarídeos podem ser obtidos de exsudatos (goma arábica e tragacante) sementes (guar, alfarroba, tamarindo) frutos (pectinas) e tubérculo (amido e inulina) (Cunha \& Feitosa, 2009). Os principais polissacarídeos conhecidos de algas marinhas são carragenanas, agaranas e alginatos. Algumas dessas macromoléculas apresentam grupos hidroxila dos resíduos de açúcar substituídos por grupamentos sulfato, sendo chamados de polissacarídeos sulfatados (Vasconcelos, et al., 2015). 
Por oferecerem vantagens de segurança, alta eficácia terapêutica, não toxicidade, baixo custo, facil acesso, boa biocompatibilidade e experiência ancestral (Niu, et al., 2020), os polissacarídeos naturais vêm mostrando grande potencial para serem utilizados como novas alternativas terapêuticas no tratamento de distúrbios gastrointestinais (DGI) (Sales, et al., 2020). Por não serem absorvidos pela mucosa do trato gastrointestinal, permanecem nela por longos períodos sem produzir efeitos sistêmicos, proporcionando vantagem substancial em relação à maioria dos medicamentos convencionais (Araújo, et al., 2020).

Os DGI são caracterizados por manifestações clínicas que acometem os tecidos e órgãos do trato gastrintestinal, como náusea, regurgitação, dor abdominal e pirose, originados a partir de uma doença de base (Pereira, et al., 2020). Dentre essas doenças com maior prevalência mundial, podemos citar a Doença do Refluxo Gastroesofágico (DRGE) no esôfago, a Gastrite e Úlcera Péptica no estômago e a Colite Ulcerativa e Diarreia no intestino. Em geral, o tratamento medicamentoso dos DGI é realizado com a utilização de inibidores de bombas de prótons (IBP), antagonistas de receptores H2, antiácidos (Sales, et al., 2020), aminossalicilatos, corticosteróides, antibióticos e antagonistas do TNF- $\alpha$ (Batista, et al., 2020). No entanto, essas opções terapeuticas disponiveis estão associadas a efeitos colaterais de gravidade variavel, podendo estender-se desde leves a graves (Pereira, et al., 2020).

Considerando que os polissacarídeos naturais vêm mostrando efeitos gastroprotetores e modulatórios gastrointestinais em uma gama de estudos pré-clinicos, o desenvolvimento de terapeuticas inovadoras utilizando essa classe de protudo natural surge como uma alternativa interessante, com poucos efeitos adversos e com capacidade de auxiliar no tratamento desses disturbios. Sendo assim, o objetivo desse trabalho foi realizar uma análise sistemática da literatura acerca dos principais efeitos dos polissacarideos naturais extraidos de plantas e algas em modelos experimentais de DGI.

\section{Metodologia}

Este estudo trata-se de uma revisão sistemática (Galvão, et al., 2019) da literatura atual, com abordagem qualitativa (Batista, et al., 2016), tendo em vista os procedimentos de análise e interpretação dos dados obtidos, realizada através de buscas nas bases de dados: Medical Literature Analysis and Retrievel System Online (Medline), Scientific Electronic Library Online (Scielo) e Biblioteca Nacional de Medicina dos Estados Unidos (PubMed), utilizando os descritores nas seguintes combinações "gum and gastric damage", "gum and antidiarrheal", "gum and gastroesophageal reflux", "gum and colitis", "sulfated polysaccharide and gastric damage", "sulfated polysaccharide and antidiarrheal", "sulfated polysaccharide and gastroesophageal reflux", "sulfated polysaccharide and colitis", "polysaccharide and gastric damage", "polysaccharide and antidiarrheal", "polysaccharide and gastroesophageal reflux" e "polysaccharide and colitis". Tal estratégia foi realizada com o intuito de encontrar o maior número possível de publicações adequadas para a revisão.

Os artigos incluídos no estudo foram somente os que estavam inclusos nas plataformas, sendo considerados artigos, teses e dissertações, incluídos e indexados no período entre 2011 e 2021, que tivessem como metodologia principal estudos experimentais, pré-clínicos em espectro de atividades in vitro e in vivo sobre os efeitos dos polissacarídeos naturais em modelos de DGI. Os demais artigos que não se enquadravam nesses critérios foram excluídos. Para análise pós-recuperação da literatura nas bases de dados, os estudos selecionados passaram por leitura criteriosa dos títulos, dos resumos e, posteriormente, dos artigos na íntegra, chegando a amostra final de 35 trabalhos. Para melhor compreensão da estratégia de busca, os métodos serão demonstrados na Figura 1. 
Figura 1: Representação esquemática da metodologia e estratégias de busca utilizada no estudo.

\section{Revisão Sistemática qualitativa}
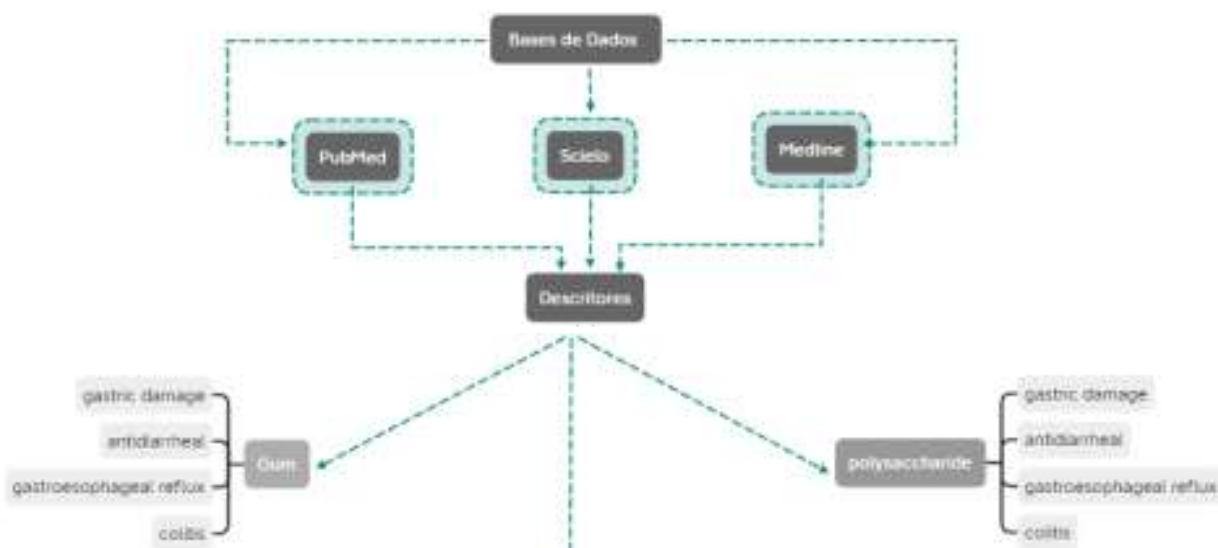

Fonte: Autores (2021).

\section{Resultados}

Os textos foram pesquisados nas bases de dados em ciências da saúde, Pubmed, MEDLINE e SciELO a partir da combinação dos descritores, e selecionados caso apresentassem relação com a temática. Após a seleção e a leitura na íntegra dos estudos, os dados foram dispostos em duas tabelas, uma para estudos com polissacarídeos extraídos de plantas (Tabela 1) e outra para os polissacarídeos extraídos de algas marinhas (Tabela 2), com prioridade para as informações relevantes da pesquisa. Os artigos foram organizados de acordo com: autor/ano, espécie do polissacarídeo, modelo experimental utilizado, principais achados e conclusão. 
Tabela 1: Principais efeitos dos polissacarídeos extraídos de plantas em modelos experimentais de DGI.

\begin{tabular}{|c|c|c|c|c|c|}
\hline AUTOR/ANO & $\begin{array}{c}\text { ESPÉCIE DO } \\
\text { POLISSACARÍDEO }\end{array}$ & MODELO EXPERIENTAL & METODOLOGIA & PRINCIPAIS ACHADOS & CONCLUSÃO \\
\hline Carvalho, et al., 2015 & Anacardium occidentale & Gastrite & $\begin{array}{l}\text { Gastrite induzida por naproxeno }(80 \mathrm{mg} / \\
\mathrm{kg}) \text {. O PL foi administrado em ratos nas } \\
\text { doses }(1,3,10 \text { e } 30 \mathrm{mg} / \mathrm{kg} \text { ), por via oral. }\end{array}$ & $\begin{array}{l}\text { Diminuiçãa dos níveis de MPO, GSH, e } \\
\text { MDA e elevaçãao da quantidade de muco } \\
\text { aderente na mucosa. }\end{array}$ & $\begin{array}{l}\text { Proteção gastrointestinal pela inibição da } \\
\text { inflamação e aumento da quantidade de } \\
\text { muco aderente na mucosa. }\end{array}$ \\
\hline Araújo, et al., 2015 & Anacardium occidentale & Diarreia & $\begin{array}{l}\text { Modelos induzidos por: I) óleo de rícino (10 } \\
\mathrm{ml} / \mathrm{kg}), \mathrm{II}) \text { óleo de rícino + prostaglandina } \\
\mathrm{E} 2(100 \mathrm{mg} / \mathrm{kg}) \text { e III) toxina da cólera }(1 \mathrm{mg} \\
\text { / alça). Ratos foram tratados com PL nas } \\
\text { doses }(30,60 \mathrm{e} 90 \mathrm{mg} / \mathrm{kg}) \text {, por via oral. }\end{array}$ & $\begin{array}{l}\text { Efeito antidiarreico no modelo I. } \\
\text { Diminuiçãao do volume da secreção de } \\
\text { fluido intestinal e da distância percorrida } \\
\text { por uma refeição de carvão no modelo II. } \\
\text { Inibição da secreção de fluido intestinal e } \\
\text { redução de íons de } \mathrm{Cl} \text { - no modelo III. }\end{array}$ & $\begin{array}{l}\text { Ação associada a inibição da motilidade } \\
\text { gastrointestinal, reduzindo o acúmulo de } \\
\text { fluido intestinal e a secreção de água e } \\
\text { íons Cl- no lúmen do intestino. }\end{array}$ \\
\hline Nicolau, et al., 2019. & Anacardium occidentale & $\begin{array}{l}\text { Doença do Refluxo } \\
\text { Gastroesofágico não erosiva }\end{array}$ & $\begin{array}{l}\text { PL a uma concentração de } 10 \% \text { por via } \\
\text { tópica foi utilizado para tratamento de } \\
\text { biópsias esofágicas humanas de pacientes } \\
\text { com DRGE e modelo cirúrgico de DRGE em } \\
\text { camundongos, induzido por subestenose } \\
\text { duodenal e exteriorização do estomago } \\
\text { (30s). }\end{array}$ & $\begin{array}{l}\text { Melhora dos parâmetros da função de } \\
\text { barreira (resistência elétrica transepitelial } \\
\text { e permeabilidade da mucosa) na mucosa } \\
\text { distal do esôfago e redução do infiltrado } \\
\text { inflamatório. }\end{array}$ & $\begin{array}{l}\text { Proteção tópica à à mucosa devido à } \\
\text { mucoadesividade } \\
\text { inflamatório. }\end{array}$ \\
\hline Figueiredo, et al., 2020 & $\begin{array}{l}\text { Alginato e Anacardium } \\
\text { occidentale (Goma de caju) }\end{array}$ & $\begin{array}{l}\text { Doença do Refluxo } \\
\text { Gastroesofágico }\end{array}$ & $\begin{array}{l}\text { Modelo induzido por subestenose duodenal } \\
\text { sobre a região pilórica. O alginato foi } \\
\text { administrado em camundongos por via oral } \\
\text { na dose }(0,3 \mathrm{~mL}) \text { e a goma de caju aplicada } \\
\text { topicamente. }\end{array}$ & $\begin{array}{l}\text { Diminuiçãa parcial (alginato) e total } \\
\text { (goma de caju) da inflamação e melhora } \\
\text { na integridade da mucosa laríngea. }\end{array}$ & $\begin{array}{l}\text { Atividade anti-inflamatória e protetora da } \\
\text { mucosa, por meio da redução de } \\
\text { episódios de refluxo gastroesofágico, } \\
\text { modificação da bolsa de ácido (alginato) } \\
\text { e aumento da resistência epitelial e } \\
\text { diminuição da permeabilidade da mucosa } \\
\text { (goma de caju). }\end{array}$ \\
\hline Batista, et al., 2020 & Morinda Citrifolia Linn & Colite & $\begin{array}{l}\text { Colite induzida por ácido acético } 6 \% \text {. } \\
\text { Camundongos foram tratados com PL nas } \\
\text { doses }(0,1,0,3 \text { e } 3,0 \mathrm{mg} / \mathrm{kg}) \text {, por via } \\
\text { intraperitoneal. }\end{array}$ & $\begin{array}{l}\text { Atenuação da migração inflamatória, do } \\
\text { peso úmido do cólon, da atividade de } \\
\text { MPO, dos níveis de GSH, MDA, NO3, } \\
\text { NO2, citocinas pró-inflamatórias e } \\
\text { expressão de COX-2. }\end{array}$ & $\begin{array}{l}\text { Ação anti-inflamatória intestinal pela } \\
\text { redução do infiltrado inflamatorio, } \\
\text { estresse oxidativo, ação pró-inflamatória } \\
\text { de citocinas e expressão de COX-2 no } \\
\text { cólon inflamado. }\end{array}$ \\
\hline Araújo, et al., 2020 & Anadenanthera colubrina & Diarreia & $\begin{array}{l}\text { Modelos induzidos por I) óleo de rícino ( } 10 \\
\mathrm{~mL} / \mathrm{kg} \text { ), II) toxina da cólera }(100 \mathrm{mg} / \mathrm{kg}) \\
\text { e III) E. coli. ( } 1 \mathrm{mg} / \mathrm{alça}) \text { O PL foi } \\
\text { administrado em camundongos nas doses } \\
(30,60 \mathrm{e} 120 \mathrm{mg} / \mathrm{kg}) \text {, por via oral. }\end{array}$ & $\begin{array}{l}\text { Diminuição do trânsito gastrointestinal, } \\
\text { das fezes diarreicas totais e } \\
\text { enteropooling. Aumento da atividade de } \\
\mathrm{Na}^{+} / \mathrm{K}^{+} \text {ATPase e bloqueio da ligação do } \\
\text { receptor de toxina GM1 }\end{array}$ & $\begin{array}{l}\text { Atividade antidiarreica associada à } \\
\text { alteração dos parâmetros fecais e redução } \\
\text { da motilidade gastrointestinal, através do } \\
\text { bloqueio físico do influxo de íons } \\
\text { extracelulares na mucosa e consequente } \\
\text { inibição das contrações do músculo liso } \\
\text { intestinal, além de atividade anti- } \\
\text { secretora devido ao bloqueio da ligação }\end{array}$ \\
\hline
\end{tabular}


Georgieva, et al., 2016. Ceratonia siliqua (Goma de alfarroba)

Cyamopsis

Takagi, et al., 2016 tetragonolobus (L.) Taub (Goma de guar)

Rosenthal, et al., 2016. Commiphora myrra L (Goma mirra)
Bebês 1-6 meses de idade com D RGE receberam fórmula com $0,33 \mathrm{~g} / 100 \mathrm{~mL}$ de goma de alfarroba solúveis no frio, durante 2 semanas.

Camundongos foram pré-alimentados com Goma Guar parcialmente hidrolisada 5\%. modelo de colite foi induzido por ácido 2,4,6-trinitrobenzenosulfônico (100 mg/ kg) dissolvido em solução de etanol a 50\%, por via intrarretal.

Monocamadas de linhas celulares de cólon humano HT-29 / B6 e Caco-2 foram ncubados com goma mirt inflamatória TNFa.

Modelo induzido por sulfato de dextran sódico $4 \%$. Camundongos foram tradados com PL na dose $(200 \mathrm{mg} / \mathrm{kg})$, por via oral.

Modelo induzido por dextran sulfato de sódio. $\mathrm{O}$ PL foi administrado em camundongos nas doses (50 e $200 \mathrm{mg} / \mathrm{kg}$ ) por via ora

Colite induzida por dextran sulfato de sódio $5 \%$. Os camundongos foram tratados com o PL nas doses $(3,10$ e $30 \mathrm{mg} / \mathrm{kg}$ ), por via oral.
Redução da exposição ao ácido esofágico, do número total diário de refluxos visíveis e mensuráveis e dos sintomas relacionados ao refluxo ácido, aumentando significativamente o peso corporal das crianças alimentadas.

Redução da atividade de MPO e da expressão do TNF- $\alpha$. Aumento da microbiota intestinal do grupo Clostridium e Bacteroides fragilis e aumento do conteúdo cecal de ácido acético, propiônico e butírico.

Inibição de todos os efeitos do $\mathrm{TNF} \alpha$ nos dois grupos celulares utilizados. Aumento da resistência transepitelial em células Caco-2.

Reduç̃o do dano a mucosa do cólon, da infiltração de células inflamatórias, do TNF- $\alpha$, dos níveis de IFN- $\gamma$ e de citocinas IL-1 $\beta$. Aumento das atividades da superóxido dismutase e da glutationa peroxidase.

Deso corporal, do índice de atividade da doença, da atividade de MPO, dos níveis de citocinas pró-inflamatórias e de Bacteroides, Proteobacteria e Staphylococcus. Melhora dos danos patológicos do cólon e uumento dos níveis de ácido acético, ácido propiônico, ácido butírico, Firmicutes, Bifidobacterium, Lactobacillus e Roseburia.

Bifidobacterium

Redução, in vivo, da gravidade da colite, da perda de peso, dos danos macroscópicos e do comprimento do cólon, além de, proteção do epitélio do cólon, promoção da manutenç̃o de enterócitos mucosos e células caliciformes secretoras de muco, conservação da homeostase do colágeno e cunservaça da homeostase do colageno de toxinas ao receptor GM1.

ormula bem tolerada por bebês e ação parcialmente atribuída a maturação gastroesofágica.

Atividade protetora antiinflamatória da mucosa do cólon através da inibição da produção de TNF- $\alpha$, aumento da microbiota produtora de ácidos graxos de cadeia curta e da proliferação de celulas Treg, induzida pelo conteudo ácido.

Efeitos de estabilização de barreira e antagonizacão de TNF $\alpha$ via inibição de sinalização PI3K e STAT6.

Potencial protetor atribuído a redução do estresse oxidativo, supressão da inflamação, modulação de numerosas vias de transdução de sinal, e indução de apoptose.

Proteção da mucosa por meio da supressão de citocinas pró-inflamatórias, proliferação de bactérias benéficas, inição de bactérias prejudiciais e aumento da função da barreira intestinal, pela regulação positiva das expressões de proteínas TJ relacionadas. Elevação dos níveis de ácido acético, ácido propiônico écido butírico estão diretamente relacionados com o aumento de ácidos graxos de cadeia curta.

Melhora da função da barreira intestinal in vivo pela redução do processo inflamatório, da permeabilidade epitelial, da secreção de citocinas e aumento da homeostase do colágeno, devido à elevação do colágeno III e baixa do colágeno I, evitando estenose e fibrose do colng do colon, esula 
Tang, et al., 2021

Su, et al., 2020

Cui, et al. 2019
Astragalus membranaceus AERP) $e$ Codonopsis
pilosula (CERP)

Schisandra chinensis

Modelo induzido por dextran sulfato de com PLS nas doses $(25,50,100 \mathrm{mg} / \mathrm{kg})$, por via oral.

Modelo induzido por dextran sulfato de sódio 2,5\%. Os camundongos foram tratados com AERP nas doses $(300,600 \mathrm{mg} / \mathrm{kg} / \mathrm{dia}) \mathrm{e}$ CERP na dose $(600 \mathrm{mg} / \mathrm{kg} / \mathrm{dia})$, por via oral.

Colite induzida por dextran sulfato de sódio na dose de $10 \mathrm{ml} / \mathrm{kg}$. O PL foi administrado em cam oral.

Modelo induzido por dextran sulfato de sódio $3 \%$. Os camundongos foram tratados com o PLS nas doses $(50,100,200 \mathrm{mg} / \mathrm{kg})$, por via oral.

Colite induzida por dextran sulfato de sódio sódio 2,5\%. Os camundongos foram tratados

redução da permeabilidade celular após a exposição à IL-1 $\beta$, diminuição da secreção de IL-8 e da expressão da claudina-1. Preservação da distribuição da occludina e aceleração da cicatrização de feridas na linha de células epiteliais Caco-2.

Coadministração de AERP e CERP melhora os sintomas clínicos, restabelece o equilibrio imunológico e alivia a lesão da mucosa do cólon.

Melhora do estado fisiológico de camundongos, regulação do nível de fatores inflamatórios e do desequilíbrio da microbiota intestinal. Aumento do conteúdo de ácidos graxos de cadeia curta.

minuição dos danos patológicos do cólon, redução do índice de atividade da doença e da atividade da MPO. Supressão das citocinas pró-inflamatórias (IL-1 $\beta$, IL-18 e TNF- $\alpha$ ), de macrófagos derivados de THP-1, de macrófagos CD11b + nos cólons e inativação da caspase- 1 em macrófagos peritoneais.

Restauração da função da barreira intestinal, diminuição do dano histológico, redução do infiltrado inflamatório e regulação da polarização de macrófagos. $3,5 \%$. O PL foi administrado em camundongos nas doses $(50,100$ e $200 \mathrm{mg} /$ $\mathrm{kg}$ ), por via oral

Manutenção da integridade da estrutura intestinal, promoção da expressão de proteínas de junção apertada no cólon. estauração mucosa também é atribuída a proliferação de células epiteliais. In vitro, seu efeito prebióticos é relacionado com a ativaç̃o de receptores Toll-like.

Eficácia única da coadministração dependente da ativação do receptor de hidrocarboneto aril e da regulação positiva do ácido isovalérico e butirato.

Recuperação da estrutura intestinal devido ao ajuste dos níveis de citocinas, melhora da diversidade e composição da microbiota intestinal e aumento significativo do conteúdo de ácido acético, ácido propiônico, ácido butírico

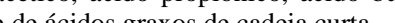

Mecanismos atribuídos a sinalização NF-kB e NLRP3 e ativaç̃a do inflamassoma. células caliciformes e dos níveis de Alivio da inibição de Bcl-2 e da superexpressão de caspase-3 e caspase-9. Restauração da expressão de Atg5, Atg7 e beclin-1, inibição dos níveis de p-akt, pMtor e do conteúdo de células dendríticas no cólon. Modulação da expressão de IL 10 nas células dendríticas.
Mecanismos associados à diminuição do estresse oxidativo e da inflamação, ativação regulada negativamente das vias de sinalização de NF-kB, STAT3 e NLRP3, melhora da expressão de proteínas de junção apertada e polarização de macrófagos M1 regulada.

Manutenção da integridade da barreira intestinal por meio do aumento da proteína TJ intestinal e das expressões das células caliciformes, via inibição da apoptose excessiva e fortalecimento da autofagia através da via Akt / mTOR. A melhora do distúrbio imunológico da mucosa está relacionada a redução do conteúdo de células dendríticas e a restauraç̃o de sura capacidade de secretar IL-10. 
Research, Society and Development, v. 10, n. 15, e524101523239, 2021

(CC BY 4.0) | ISSN 2525-3409 | DOI: http://dx.doi.org/10.33448/rsd-v10i15.23239

Cheng, et al., 2020

Angelica sinensi

Colite

Astragalus membranaceus

Colite
Colite induzida por dextran sulfato de sódio 2,5\%. O PL foi administrado em camundongos na dose $(200 \mathrm{mg} / \mathrm{kg})$ por via

Modelo induzido por dextran sulfato de
sódio $3 \%$. Os camundongos foram tratados com PLS na dose $(200 \mathrm{mg} / \mathrm{kg})$, por via intraperitoneal.
Melhorar dos sintomas de perda de peso, Atividade protetora e anti-inflamatória pontuação do índice de atividade da pela inibição de citocinas inflamatórias, doença, encurtamento do cólon e diminuição da apoptose de celulas expressões de proteínas de junção epiteliais intestinais e promoção da apertada (zona ocludente 1, ocludina e expressão da proteína TJ.

claudina-1). Supressão da atividade da

MPO, das citocinas pró-inflamatoris (IL-

6, IL-1 $\beta$, e TNFo e reduça dos evect apoptóticos. Melhora do índice de atividade da doença

peso e comprimento do cólon. Efeito protetor mediado pela inibição da
ativação do NF-kB, que por sua vez, desregula respostas pró-inflamatórias nos tecidos do cólon

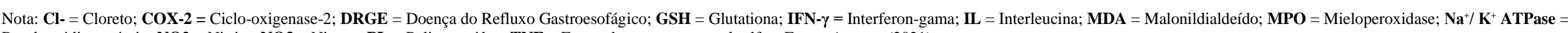
Bomba sódio potássio; $\mathbf{N O 2}=$ Nitrito; NO3 $=$ Nitrato $; \mathbf{P L}=$ Polissacarídeo; $\mathbf{T N F}=$ Factor de necrose tumoral- alfa. Fonte: Autores (2021). 
Tabela 2: Principais efeitos dos polissacarídeos extraídos de algas em modelos experimentais de DGI.

\begin{tabular}{|c|c|c|c|c|c|}
\hline AUTOR/ANO & $\begin{array}{c}\text { ESPÉCIE DO } \\
\text { POLISSACARÍDEO }\end{array}$ & $\begin{array}{c}\text { MODELO } \\
\text { EXPERIENTAL }\end{array}$ & METODOLOGIA & PRINCIPAIS ACHADOS & CONCLUSÃO \\
\hline Brito, et al., 2014 & Gracilaria birdiae & Colite & $\begin{array}{l}\text { Colite induzida por ácido trinitrobenzenossulfônico } \\
(800 \mathrm{~mL}) \text { dissolvido em solução de etanol a } 50 \% \text {, por } \\
\text { via intrarretal. Os ratos foram tratados com o PLS nas } \\
\text { doses }(30,60 \mathrm{e} 90 \mathrm{mg} / \mathrm{kg}, 500 \mathrm{ml}) \text {, por via oral. }\end{array}$ & $\begin{array}{l}\text { Redução do consumo de GSH, dos níveis de } \\
\text { citocinas pró-inflamatórias, do infiltrado } \\
\text { inflamatório, das concentrações de MDA, NO3, NO2 } \\
\text { e da atividade de MPO. }\end{array}$ & $\begin{array}{l}\text { Diminuição dos danos intestinais por meio } \\
\text { da inibição do infiltrado inflamatório, } \\
\text { liberação de citocinas e peroxidação lipídica. }\end{array}$ \\
\hline Silva, et al., 2012 & Gracilaria birdiae & Gastrite & $\begin{array}{l}\text { Modelo induzido por naproxeno }(80 \mathrm{mg} / \mathrm{kg}) . \text { Ratos } \\
\text { foram tratados com PLS nas doses }(10,30 \mathrm{e} 90 \mathrm{mg} / \\
\mathrm{kg}) \text {, por via oral. }\end{array}$ & $\begin{array}{l}\text { Inibição da infiltração inflamatória, da peroxidação } \\
\text { lipídica e redução dos níveis de MPO, GSH e MDA. }\end{array}$ & $\begin{array}{l}\text { Efeito protetor por meio da inibição do } \\
\text { infiltrado inflamatório e peroxidação lipídica. }\end{array}$ \\
\hline Silva, et al., 2011 & Gracilaria caudata & Gastrite & $\begin{array}{l}\text { Dano gástrico induzido por etanol a } 50 \% \text {. O PLS foi } \\
\text { administrado em camundongos nas doses ( } 3,10,30 \text { e } \\
90 \mathrm{mg} / \mathrm{kg} \text { ), por via oral. }\end{array}$ & $\begin{array}{l}\text { Diminuição da produção de radicais livres e } \\
\text { peroxidação lipídica. }\end{array}$ & $\begin{array}{l}\text { Efeito protetor gástrico pela ativação da via } \\
\mathrm{NO} / \mathrm{K} \text { (ATP). }\end{array}$ \\
\hline Dutra, et al., 2021 & Gracilaria caudata & Colite & $\begin{array}{l}\text { Modelo induzido por ácido acético } 6 \%(200 \mathrm{~mL}) \text {, por } \\
\text { via intrarretal. Camundongos foram tratados com } \\
\text { PLS nas doses }\left(\begin{array}{llllll}3 & \text { e } & 10 & \mathrm{mg} / \mathrm{kg}), \text { por via } \\
\text { intraperitoneal. }\end{array}\right.\end{array}$ & $\begin{array}{l}\text { Redução do infiltrado inflamatório, do peso úmido, } \\
\text { da MPO, do consumo de GSH, das concentrações de } \\
\text { MDA, NO3, NO2, IL-1 } \beta \text {, TNF- } \alpha \text { e da expressão de } \\
\text { iNOS. }\end{array}$ & $\begin{array}{l}\text { Ação atribuída a atividade anti-inflamatória e } \\
\text { antioxidante e a redução de citocinas pró- } \\
\text { inflamatórias e expressão de iNOS. }\end{array}$ \\
\hline Sales, et al., 2020 & Gracilaria caudata & $\begin{array}{c}\text { Esofagite Erosiva e } \\
\text { Doença do Refluxo } \\
\text { Gastroesofagico não } \\
\text { Erosiva } \\
\end{array}$ & $\begin{array}{l}\text { Biópsias esofágicas obtidas de pacientes com DRGE } \\
\text { foram tratadas com PLS nas doses }(1,0,3 \text { ou } 1 \%) \text {. }\end{array}$ & 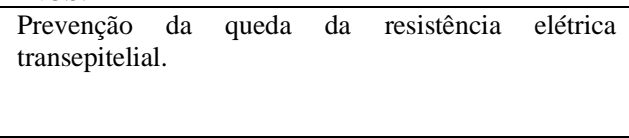 & $\begin{array}{l}\text { Efeito protetor da barreira mucosa esofágica } \\
\text { pela eliminação ou deslocamento da bolsa de } \\
\text { ácido e aumento da barreira epitelial. }\end{array}$ \\
\hline $\begin{array}{l}\text { Leódido, et al., } \\
2017\end{array}$ & Gracilaria intermedia & Diarreia & $\begin{array}{l}\text { Modelos induzidos por I) óleo de rícino }(10 \mathrm{ml} / \mathrm{kg}) \text {, } \\
\text { II) toxina da cólera }(1 \mu \mathrm{g}) \text { e III) Escherichia coli }(5 \mathrm{ml} \\
/ \mathrm{kg}) \text {. Os ratos foram tratados com PLS nas doses }(3 \text {, } \\
10,30 \mathrm{mg} / \mathrm{kg}) \text {, por via oral. }\end{array}$ & $\begin{array}{l}\text { Diminuição do trânsito gastrointestinal, do total de } \\
\text { fezes, fezes diarreicas totais e enteropooling ( } 30 \mathrm{mg} / \\
\mathrm{kg} \text { ). Aumento da atividade da Na/K-ATPase e } \\
\text { redução da diarreia induzida por E. coli, evitando } \\
\text { perda de peso nos animais. }\end{array}$ & $\begin{array}{l}\text { Mecanismos de ação associados a } \\
\text { anticolinérgicos e a interação com receptores } \\
\text { GM1 da toxina da cólera. }\end{array}$ \\
\hline $\begin{array}{l}\text { Sousa, et al., } \\
\quad 2016\end{array}$ & Hypnea musciformis & Diarreia & $\begin{array}{l}\text { Modelos induzidos por I) óleo de rícino }(10 \mathrm{ml} / \mathrm{kg}) \\
+ \text { PGE2 }(100 \mu \mathrm{g} / \mathrm{kg}) \text { e II) toxina da cólera }(1 \mu \mathrm{g})+ \\
\text { Cl-. Ratos e camundongos foram tradados com PLS } \\
\text { nas doses }(10,30 \mathrm{e} 90 \mathrm{mg} / \mathrm{kg}) \text {, por via oral. }\end{array}$ & $\begin{array}{l}\text { Redução de enteropooling e do trânsito } \\
\text { gastrointestinal e aumento da atividade Na/K- } \\
\text { ATPase nos modelos I e II. Bloqueio da ligação do } \\
\text { receptor de toxina GM1 no modelo II. }\end{array}$ & $\begin{array}{l}\text { Ação antidiarreica pelo aumento da atividade } \\
\text { Na/K - ATPase, inibição da motilidade } \\
\text { gastrointestinal, via ativação de receptores } \\
\text { colinérgicos e bloqueio da ligação do } \\
\text { receptor GM1-toxina. }\end{array}$ \\
\hline $\begin{array}{c}\text { Monturil, et al., } \\
2020\end{array}$ & $\begin{array}{l}\text { Digenea simplex (Wulfen) } \\
\quad \text { C. Agardh } 1822\end{array}$ & Colite & 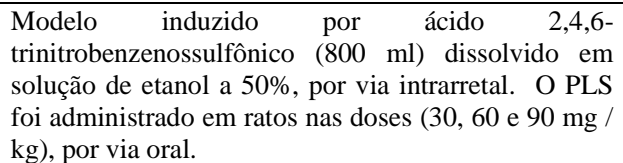 & $\begin{array}{l}\text { Redução do peso úmido, dos escores macro e } \\
\text { microscópicos das lesões, da atividade da MPO, dos } \\
\text { níveis de citocinas pró inflamatórias, MDA, NO3 e } \\
\text { NO2. }\end{array}$ & $\begin{array}{l}\text { Ação anti-inflamatória e antioxidante atravez } \\
\text { da redução do estresse oxidativo, inibição da } \\
\text { produção de citocinas pró-inflamatórias e } \\
\text { migração de neutrófilos. }\end{array}$ \\
\hline $\begin{array}{l}\text { Carneiro, et al., } \\
2018 .\end{array}$ & Caulerpa mexicana & Gastrite & $\begin{array}{l}\text { Gastrite induzida por etanol absoluto }(0,2 \mathrm{~mL}) \text {. Os } \\
\text { camundongos foram tratados com PLS nas doses }(2 \text {, } \\
20 \text { e } 200 \mathrm{mg} / \mathrm{kg}) \text {, por via oral. }\end{array}$ & $\begin{array}{l}\text { Redução do dano gástrico e normalização dos níveis } \\
\text { elevados de substâncias reativas ao ácido } \\
\text { tiobarbitúrico e dos niveis de GSH. }\end{array}$ & 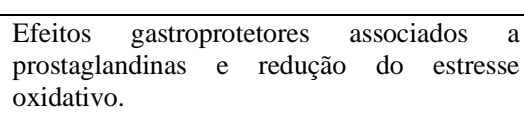 \\
\hline $\begin{array}{l}\text { Bezerra, et al., } \\
2018 .\end{array}$ & Gracilaria cervicornis & Diarreia & $\begin{array}{l}\text { Diarreia aguda induzida por óleo de rícino }(10 \mathrm{~mL} / \\
\mathrm{kg}) \text { e diarreia secretora induzida por toxina da cólera. } \\
\text { O PLS foi administrado em camundongos nas doses } \\
(0,3,1 \text { e } 3 \mathrm{mg} / \mathrm{kg} \text { ), por via oral. }\end{array}$ & $\begin{array}{l}\text { Redução do número total de produção fecal, fezes } \\
\text { diarreicas, acúmulo de fluido intestinal na diarreia } \\
\text { aguda e secretora. Aumento da atividade } \mathrm{Na}^{+} / \mathrm{K}^{+}- \\
\text {ATPase do intestino delgado na diarreia aguda, e } \\
\text { diminuição de cloreto no intestino delgado na } \\
\text { diarreia secretora. }\end{array}$ & $\begin{array}{l}\text { Efeito antidiarreico associado a atividade } \\
\mathrm{Na}^{+} / \mathrm{K}^{+} \text {-ATPase na diarreia aguda e } \\
\text { associado a ligação ao GM1 e / ou toxina da } \\
\text { cólera, bloqueando sua fixação à superfície } \\
\text { celular do enterócito na diarreia secretora. }\end{array}$ \\
\hline
\end{tabular}




\begin{tabular}{|c|c|c|c|c|c|}
\hline $\begin{array}{l}\text { Lucena, et al., } \\
2018 .\end{array}$ & Caulerpa sp. & Colite & $\begin{array}{l}\text { Colite induzida por dextran sulfato de sódio } 3 \% \text {. Os } \\
\text { camundongos foram tratados com PLS nas doses ( } 40 \\
\text { e } 4 \mathrm{mg} / \mathrm{kg} \text { ), por via oral. }\end{array}$ & $\begin{array}{l}\text { Melhora dos sinais clínicos, diminuição do } \\
\text { encurtamento e dano do cólon, redução dos níveis de } \\
\text { TNF- } \alpha \text {, IFN- } \gamma \text {, IL-6, IL-17 e NFkB p65 e aumento } \\
\text { dos níveis de IL-10 no tecido. }\end{array}$ & $\begin{array}{l}\text { Atividade anti-inflamatória } \text { atribuída } \\
\text { inibição da ativação da via do NF-kB. }\end{array}$ \\
\hline $\begin{array}{l}\text { Sousa, et al., } \\
\quad 2016\end{array}$ & Solieria filiformis & Gastrite & $\begin{array}{l}\text { Gastrite induzida por etanol } 50 \% \text {. O PLS foi } \\
\text { administrado em camundongos nas doses }(0.3,1,3 \text {, e } \\
10 \mathrm{mg} / \mathrm{kg} \text { ), por via oral. }\end{array}$ & $\begin{array}{l}\text { Redução do dano gástrico, aumento dos níveis de } \\
\text { GSH e diminuição dos níveis de MDA e } \\
\text { hemoglobina. }\end{array}$ & $\begin{array}{l}\text { Mecanismos gastroprotetores relacionados } \\
\text { aos níveis de GSH e MDA e potencial } \\
\text { antioxidante, in vivo e in vitro, causada por } \\
\text { um antioxidante secundário, com ions } \\
\text { ferrosos e atividade quelante do radical } \\
\text { hidroxila. }\end{array}$ \\
\hline $\begin{array}{l}\text { Damasceno, et } \\
\text { al., } 2013\end{array}$ & $\begin{array}{l}\text { Hypnea musciformis } \\
\text { (Wulfen) JV } \\
\text { Lamour. (Gigartinales- } \\
\text { Rhodophyta) }\end{array}$ & Gastrite & $\begin{array}{l}\text { Dano gástrico induzido por etanol 50\%. Os } \\
\text { camundongos foram tratados com fração de PLS (3, } \\
10,30 \text { e } 90 \mathrm{mg} / \mathrm{kg} \text { ), por via oral. }\end{array}$ & $\begin{array}{l}\text { Diminuição do dano hemorrágico, edema, perda de } \\
\text { células epiteliais, infiltração de células inflamatórias } \\
\text { e níveis de GSH. Aumento de MDA. }\end{array}$ & $\begin{array}{l}\text { Efeito protetor contra o dano gástrico } \\
\text { mediado pela ativação da via } \mathrm{NO} / \mathrm{K} \text { ATP } \mathrm{e} \\
\text { mecanismos que envolvem a redução da } \\
\text { peroxidação lipídica. }\end{array}$ \\
\hline Costa, et al., 2016 & Gracilaria caudata & Diarreia & $\begin{array}{l}\text { I)Diarreia aguda induzida por óleo de mamona ( } 10 \\
\mathrm{~mL} / \mathrm{kg} \text { ) e II) Diarreia secretora provocada pela } \\
\text { toxina da colera ( } 1 \mathrm{mg} / \mathrm{alcca} \text { ). O PLS foi administrado } \\
\text { em ratos nas doses }(10,30 \mathrm{e} 90 \mathrm{mg} / \mathrm{kg} \text { ), por via oral. }\end{array}$ & $\begin{array}{l}\text { Redução da massa fecal, fezes diarreicas, } \\
\text { enteropooling e trânsito gastrointestinal, nos modelos } \\
\text { I e II, e interação do PLS com receptor GM1 e toxina } \\
\text { da colera, no modelo II. }\end{array}$ & $\begin{array}{l}\text { Melhora da diarreia por mecanismos } \\
\text { colinérgicos (modelo I) e pela interaçãa com } \\
\text { toxina da cólera e receptor GM1 (modelo II). }\end{array}$ \\
\hline $\begin{array}{l}\text { Zhang, et al., } \\
2020\end{array}$ & Flammuliana velutipes & Colite & $\begin{array}{l}\text { Colite induzida por sulfato de dextrana de sódio } \\
4,5 \% \text {. Os ratos foram tratados com PLS nas doses } \\
(50,100,200 \mathrm{mg} / \mathrm{kg}) \text {, por via oral. }\end{array}$ & $\begin{array}{l}\text { Regulação da disbiose microbiana colônica, } \\
\text { promoção dos níveis de ácidos graxos de cadeia curta } \\
\text { cecal, redução da inflamação e melhora do ganho de } \\
\text { peso, da consistência das fezes e de sangramentos. }\end{array}$ & $\begin{array}{l}\text { Atividade probiótica pela redução de } \\
\text { patógeno oportunista e elevação de bactérias } \\
\text { protetoras. Diminuiçãa dos sintomas da } \\
\text { colite atribuídos a atividade anti-inflamatória } \\
\text { através da regulação negativa da via de sinal } \\
\text { TLR4 \NF-kB. }\end{array}$ \\
\hline Brito, et al., 2016 & Hypnea musciformis & Colite & $\begin{array}{l}\text { Colite induzida pelo ácido trinitrobenzenossulfônico } \\
\text { dissolvido em soluçãa de etanol a } 50 \% \text {. Os ratos } \\
\text { foram tratados com PLS as doses }(10,30 \text {, e } 60 \\
\mathrm{mg} / \mathrm{kg} \text { ), por via oral. }\end{array}$ & $\begin{array}{l}\text { Diminuição dos escores macroscópicos, do peso } \\
\text { úmido, GSH, MDA MPO, NO2/NO3 e citocinas } \\
\text { inflamatórias. }\end{array}$ & $\begin{array}{l}\text { Atividade anti-inflamatória e redução do } \\
\text { processo oxidativo através da inibição da } \\
\text { migração de celulas inflamatórias e sîntese e } \\
\text { liberação de produtos da inflamação. }\end{array}$ \\
\hline
\end{tabular}

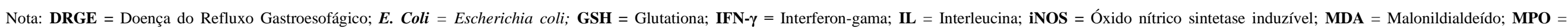
Mieloperoxidase $; \mathbf{N a}^{+} / \mathbf{K}^{+}$ATPase $=$Bomba sódio potássio $; \mathbf{N O 2}=$ Nitrito $; \mathbf{N O 3}=$ Nitrato $; \mathbf{P L S}=$ Polissacarídeo Sulfatado $; \mathbf{T N F} \boldsymbol{\alpha}=$ Factor de necrose tumoral- alfa

Fonte: Autores (2021). 


\section{Discussão}

Dentro do tema de estudo proposto, foi possível selecionar artigos majoritariamente experimentais, onde foi realizada uma análise sistemática da literatura acerca dos principais efeitos dos polissacarídeos naturais extraídos de plantas e algas em modelos experimentais de Doença do Refluxo Gastroesofágico, Gastrite, Colite e Diarreia.

A Doença do Refluxo Gastroesofágico consiste em uma condição clínica desenvolvida quando o conteúdo gástrico realiza fluxo retrogrado e retorna para o esôfago, causando sintomas como pirose, regurgitação e dor (Henry, 2014). Os inibidores da bomba de prótons são o tratamento de primeira linha para pacientes com DRGE. No entanto, cerca de $30 \%$ dos pacientes não respondem muito bem a esses medicamentos. Nestes casos, os anti-histamínicos H2 ou antagonistas do receptor H2 e antiácidos são usados com terapia adjuvante para controlar os sintomas da DRGE, porém, não possuem boa tolerância e atuam de modo parcial na redução da secreção de ácido (Sales, et al., 2020).

A mucosa do esôfago é constituída por epitélio escamoso estratificado que funciona como uma barreira defensiva resistente contra componentes deletérios do refluxo gastroesofágico. Porém, a nível celular e molecular, injurias na integridade da barreira que possibilitam a infiltração de substâncias lesivas como ácido gástrico e outros componentes em camadas mais intimas do epitélio, são atribuídos a patogênese dos sintomas do refluxo gastroesofágico. A integridade da mucosa é funcionalmente avaliada pela Resistência Elétrica Transepitelial e pela medida de permeabilidade transcelular de cargas através da mucosa (Bingana, et al., 2020). Neste sentido, substâncias que pudessem atuar como protetor da mucosa, agindo de forma local, mantendo a integridade das junções celulares e dando proteção tópica ao tecido poderiam ser utilizadas como alternativas terapêuticas. Dentre as substâncias que atendem tais requisitos, pode-se citar os alginatos,

Os alginatos são polissacarídeos extraídos de diversas espécies de algas marinhas marrons, onde agem como componente estrutural na parede celular e nos espaços intracelulares, promovendo rigidez e ao mesmo tempo flexibilidade à parede (Garcia-Cruz, et al., 2008). Constituído de ácidos $\alpha$-L-gulurônicos e $\beta$-D-manurônicos, são amplamente utilizados pela indústria alimentícia, conferindo aos alimentos propriedades de textura, como espessamento, aderência, emulsicação, gelicação ou volume (Brasil, 2013). Estudos mostraram que o tratamento com polissacarídeos alginatos em modelos de DRGE foi capaz de reverter os danos à mucosa, quando comparado aos grupos controles. Em um trabalho desenvolvido por Figueiredo e Colaboradores (2020) em camundongos, o alginato diminuiu parcialmente a inflamação laríngea e melhorou drasticamente a integridade da mucosa, por meio da redução de episódios de refluxo gastroesofágico e modificação da bolsa de ácido, termo que refere-se a presença de uma camada de acido sobrenadando o topo do conteúdo gastrico imediatamente abaixo da junção gastroesofagica (Romãozinho, et al., 2014). A goma de cajueiro, também avaliada no experimento, apresentou resultados superiores prevenindo completamente a inflamação e o comprometimento da função da barreira mucosa, como consequência do aumento da resistência elétrica trasepitelial e da diminuição da permeabilidade da mucosa, conclusão identica as obtidas por Nicolau (2019), em modelos utilizando biópsias esofágicas humanas e cirúrgico em camundongos. Diferente do alginato, a goma do cajueiro é um heteropolissacarídeo complexo de origem vegetal produzidos pelas células epiteliais de cajueiros (Anacardium occidentale) em resposta a agressões físicas ou microbianas ao córtex, sendo constituída quimicamente por: $\beta$-Dgalactose, $\alpha$-D-glucose, arabinose, ramnose e ácido glucurônico (Andrade, et al., 2013), com funções espessantes, gelificantes, emulsificantes, estabilizantes, aglutinantes, com capacidade de controle de cristalização, inibição de sinérese, encapsulação e formação de filmes (Araújo, et al., 2018).

Percebe-se que os estudos com polissacarídeos de algas em modelos de DRGE são bem mais presentes que as pesquisas com polissacarídeos e origem vegetal. Essa tendência se dá, provavelmente devido as características químicas dessas macromoléculas que apresentam grupamentos sulfato associados aos seus resíduos de açúcar (conferindo-lhes carga negativa) sendo chamados de polissacarídeos sulfatados, criando um ambiente favorável para interação eletrostática com os componentes 
do muco naturalmente presente na mucosa do esôfago (Vasconcelos, et al., 2015). Dentre esses polissacarídeos sulfatados, os espécimes do gênero Gracilaria ganham bastante destaque. A Gracilaria caudata, por exemplo, é uma alga típica de regioes entremarés, com ampla distribuição na costa brasileira (Avres-Ostrock, et al., 2014), constituída, principalmente, por polissacarídeos sulfatados (Costa, 2016), aminoácidos tipo micosporina (MAAs), ácido hexadecanoico, n-heptadecano, colesterol e fitona. Atualmente, desempenham um importante papel social e econômico por meio da extração de ficocolóides, alimentação direta, produção de artesanato e cosméticos (Torres, et al., 2017). Em estudos conduzidos por Sales e colaboradores (2020), o tratamento de biópsias esofágicas obtidas de pacientes com DRGE com polissacarídeo extraído de Gracilaria caudata também obteve efeito protetor da barreira mucosa esofágica pelo deslocamento da bolsa de ácido, aumento da barreira epitelial e prevenção da queda da resistência elétrica transepitelial, mantendo a integridade das junções celulares do epitélio que compõe a mucosa.

Dente os polissacarídeos de planta utilizados em ensaios clínicos de DRGE a presente pesquisa também encontrou estudos com espécimes do gênero Ceratonia. Nativa de climas subtropicais e com ampla utilização na indústria alimentícia e na medicina, a Ceratonia siliqua L, conhecida popularmente como alfarrobeira, é uma planta com reduzido teor de lipídeos, baixo índice glicêmico, alta quantidade de fibras naturais e de elevado valor nutritivo (dos Santos Silva, et al., 2018). Uma fórmula espessada de goma de alfarroba solúvel no frio foi ingerida por bebês de 1-6 meses de idade com RGE, durante 2 semanas. Os experimentos mostraram que a fórmula foi eficaz na redução da exposição ao ácido esofágico, no número total diário de refluxos visíveis e mensuráveis e sintomas relacionados ao refluxo ácido, aumentando significativamente o peso corporal das crianças alimentadas, demonstrando o grande potencial dos polissacáridos em estudos clínicos, aumentando a perspectiva de um dia tais produtos naturais possam chegar às prateleiras (Georgieva, et al., 2016).

Dentre os DGI pode-se afirmar que a gastrite representa um dos distúrbios de maior prevalência entre a população em geral (Pereira, et al., 2020). A gastrite é uma patologia definida por alterações histológicas no revestimento do estômago, onde se observa infiltrado de células inflamatórias (Silva, et al., 2018). Lesões da mucosa gástrica podem ser focal ou difusa, superficial ou potencialmente resultando em ulceração ou hemorragia gástrica, que está associada à significativa morbidade e mortalidade (Kakagia, et al., 2020). De distribuição universal, a gastrite é prevalente em cerca de 50\% da população mundial (Ddine, et al., 2020). Sua etiologia está associada à infecção pela Helicobacter pylori (H. pylori), uso prolongado de antiinflamatórios não-esteróides (AINEs), origem autoimunes e relacionadas ao uso de álcool e drogas (Dias, et al., 2015). Os principais sintomas são representados por dor epigástrica, pirose, náuseas, vômitos, sensação de saciedade precoce e desconforto abdominal (Barbosa, et al., 2010). O Omeprazol tem sido utilizado como medicamento padrão no tratamento de danos gástricos e na prevenção de úlcera péptica desde 1989, entretanto tem sido associado a efeitos adversos e interações medicamentosas (Kakagia, et al., 2020).

Os mecanismos de proteção natural da mucosa gastrica são representados por fatores de defesa como secreção de muco/bicarbonato; proteção epitelial; microcirculação através da angiogênese; produção de prostaglandinas (PGE2 e PGI2) e pelo sistema antioxidante. As células epiteliais superficiais do estomago são responsaveis pela secreção de muco, bicarbonato e prostaglandinas. A camada firme de muco e bicarbonato atua evitando o contato do ácido clorídrico com as células epiteliais. As prostaglandinas, por sua vez, age estimulando a secreção de muco e bicarbonato, reduzindo a secreção de ácido clorídrico e elevando o fluxo sangüíneo da mucosa gástrica. Quando ácidos ou outros agentes irritantes entram na camada subepitelial, neurônios aferentes sensoriais induzem o aumento no fluxo sanguíneo da mucosa, possibilitando a sua rápida retirada e limitando a penetração em camadas mais profundas. Na presença de agressão aguda à mucosa gástrica, células epiteliais iniciam o proceso de recontrução e há a formação de nova microcirculação capilar, importante para o suporte de oxigênio e nutrientes para a regeneração da mucosa. A defesa pelo sistema atioxidante se dá, incialmente, pelas enzimas superóxido dismutase (SOD), catalase (CAT) e glutationa peroxidase (GPx), que atuam contra superóxido e peróxido de hidrogênio, e em 
segundo momento por vitaminas, flavonóides, carotenóides, ácido úrico e glutationa (GSH) (Lucetti, 2014; Bighetti, et al., 2002).

$\mathrm{O}$ desequilíbrio desses mecanismos citoprotetores, diminuem a resistência das células e facilitam o acesso dos agentes agressores a elas. A gastrite crônica por AINEs, prevalente em 25-50\% dos usuários, ocorre devido à inibição da enzima COX1 e 2, responsável pela secreção basal de prostaglandinas, sobretudo da prostaglandina $E_{2}$ (Heringer, et al., 2018). A ingestão constante de bebidas alcoólicas, por exemplo, pode provocar lesão corrosiva resultante do rompimento da barreira da mucosa gástrica e, como consequência, a retrodifusão dos íons H+ (Oliveira, et al., 2012.).

Estudos realizados com a Goma de Cajueiro, em modelo experimental de gastrite, mostraram proteção gastrointestinal pela inibição da inflamação e aumento da quantidade de muco aderente na mucosa, em ratos (Carvalho, et al., 2015). A atividade anti-inflamatória também foi observada por Silva (2012), utilizando Gracilaria birdiae, e potencial oxidante por meio da inibição da peroxidação lipídica. Outras pesquisas, verificaram a atividade antioxidante no tratamento com as algas marinhas Gracilaria caudata (Silva, et al., 2011) e Hypnea musciformis (Damasceno, et al., 2013), mediada pela ativação da via NO/K-ATP; Solieria filiformis (Sousa, et al., 2016), causada por um antioxidante secundário, com íons ferrosos e atividade quelante do radical hidroxila e Caulerpa mexicana (Carneiro, et al., 2018) associado a ação das prostaglandinas.

Ao analisar estes resultados pode-se observar uma padrão: os principais mecanismos de ação dos polissacarídeos na proteção das mucosas até então envolve de certa forma efeitos antiinflatórios e antioxidantes. Sendo assim, era esperado que tais produtos naturais tivessem êxito em tratar distúrbios intestinais que envolvessem algum tipo de processo inflamatório, sendo a colite ulcerativa um ótimo exemplo. A colite ulcerativa é uma doença inflamatória intestinal crônica e inespecífica que afeta o cólon e reto através da formação de úlceras na mucosa intestinal e submucosa (Batista, et al., 2020). De etiologia multifatorial, está intimamente relacionado à microbiota intestinal, distúrbios do sistema imunológico, fatores hereditários, ambientais e psicológicos (Niu, et al., 2021). As manifestações clinicas frequentes incluem urgência fecal, sangramento retal, abdominal dor, diarreia, febre, fadiga e perda de peso (Batista, et al., 2020), que podem evoluir com anemia, emagrecimento, hipoproteinemia, distúrbios hídricos e eletrolíticos (Niu, et al., 2021). A terapia padrão para colite busca reduzir a inflamação anormal no revestimento do cólon e aliviar a sintomatologia por meio do uso de aminossalicilatos, corticosteróides, antibióticos e antagonistas do TNF- $\alpha$ (Batista, et al., 2020). No entanto, esses medicamentos mostram eficácia limitada para remissão de longo prazo e são associados a efeitos colaterais significativos (Dutra, et al., 2021).

Nos modelos experimentais, os agentes mais utilizados para induzir a colite são o sulfato de dextran sódico (DSS), ácido 2,4,6-trinitrobenzenosulfônico (TNBS) e o ácido acético (Su, et al., 2020; Taya, et al., 2016; Maria-Ferreira, et al., 2018). $\mathrm{O}$ agente DSS, provoca danos à barreira epitelial do cólon induzindo uma resposta imune exacerbada, porém o exato mecanismo não está esclarecido (Taya, et al., 2016; Maria-Ferreira, et al., 2018). O ácido acético, induz a um processo inflamatório e necrotizante difuso, agudo, geralmente limitado à mucosa e submucosa, que resulta em resposta mais favorável quanto a profundidade e extensão das lesões (Dutra, et al., 2021). Já o TNBS atua como um hapteno, que na sua forma solúvel livre, não pode estimular as células B e, por este motivo, não é considerada imunogênica, todavia, quando acoplada à uma proteína carreadora, o complexo hapteno-carreador ativa não apenas as células $\mathrm{B}$, como também as células $\mathrm{T}$ auxiliares, e estimula a via de produção de anticorpos. Logo, o TNBS ao se ligar às proteínas teciduais pode desencadear uma resposta imunológica muito parecida com o que ocorre nos casos de colite (Monturil, et al., 2020).

Os resultados dos estudos experimentais utilizando esses modelos de colite demonstram que o tratamento com polissacarídeos extraídos de plantas e algas reduz a gravidade da inflamação (Cui, et al., 2021; Su, et al., 2020; Maria-Ferreira, et al., 2018). Segundo, Maria-Ferreira (2018), a o tratamento com o polissacarídeo da planta Acmella oleracea, protege o epitélio do cólon e promove a manutenção de enterócitos mucosos e células caliciformes produtoras de muco, além de conservar a homeostase do colágeno e aumentar a proliferação celular, resultando na redução da gravidade da colite. Conforme 
o estudo de Cui e Colaboradores (2021) o efeito do PL da planta Scutellaria baicalensis Georgi, o SP2-1, atenua a perda de peso corporal, reduz o índice de atividade da doença (DAI), melhora o dano patológico do cólon e também suprime os níveis de citocinas pró-inflamatórias, tornando o SP2-1 um novo candidato a medicamento contra a colite. O PL extraído de um outro espécime do gênero Scutellaria (SP1-1) também mostrou resultados promissores, diminuindo significativamente o índice de atividade da doença e melhorando os danos patológicos do cólon por meio da supressão da liberação de citocinas próinflamatórias, redução do infiltrado inflamatorio e controle do estresse oxidativo (Cui, et al., 2019). Resultados semelhantes podem ser observados também em estudos conduzidos por outros autores com a utilização de variadas espécies vegetais: Morinda Citrifolia Linn (Batista, et al., 2020); Cyamopsis tetragonolobus (L.) Taub. (Takagi, et al., 2016); Commiphora myrra L (Rosenthal, et al., 2016.); Amphipterygium adstringens (Rodriguez, et al., 2016.); Astragalus membranaceus e Codonopsis pilosula (Tang, et al., 2021); Schisandra chinensis (Su, et al., 2020); Dictyophora indusiata (Wang, et al., 2019); Ganoderma atrum (Zheng, et al., 2020); Astragalus membranaceus (Lv, et al., 2017); e Angelica sinensis (Cheng, et al., 2020).

Esse padrão anti-inflamatório e antioxidante também pode ser observado em estudos conduzidos com algas marinhas como: Hypnea musciformis (Brito, et al., 2016); Flammuliana velutipes (Zhang, et al., 2020); Caulerpa sp. (Lucena, et al., 2018); Digenea simplex (Wulfen) C. Agardh (Monturil, et al., 2020); Gracilaria caudata (Dutra, et al., 2021); e Gracilaria birdiae (Brito, et al., 2014). A análise dos estudos mostrou que uso de polissacarídeos para tratamento de colite tem muitas vantagens, tais como segurança, efeitos definitivos e poucas reações adversas. Os polissacarídeos podem aliviar a colite, regulando os níveis de células do sistema imunológico, interferindo na transdução da via de sinalização, regulando a secreção de citocinas inflamatórias e abundância da microbiota intestinal além de proteger a barreira imunológica da mucosa intestinal.

Por fim, dentre os DGI a diarreia representa o principal sintoma associado à patologias que afetam a mucosa do intestino. A diarreia é um distúrbio gastrointestinal caracterizado por um rápido trânsito do conteúdo gástrico através do intestino, levando a um aumento no número de evacuações, três ou mais vezes por dia, com um aumento na taxa de fluxo de fezes e / ou a presença de sangue e muco, acompanhados por aumento da secreção e diminuição da absorção de fluidos, levando à perda de água e eletrólitos (Araújo, et al., 2015). Considerada um problema de grande relevância epidemiológica no mundo, as doenças diarreicas constituem a sétima maior causa de mortalidade infantil (França, et al., 2017), principalmente nos países em desenvolvimento ou emergentes, sendo responsáveis pelo acometimento a nível mundial de aproximadamente 1,3 bilhões de crianças abaixo de cinco anos e 4 milhões de mortes anualmente (Araújo, et al., 2010). Atualmente, não há tratamento farmacológico eficaz para diarreia, e o tratamento disponível é inespecífico e geralmente visa reduzir o desconforto, desidratação e inconveniência causada por evacuações frequentes (Sousa, et al., 2016).

Nos estudos pré-clínicos que envolvem a pesquisa de substâncias antidiarreicas o principal modelo experimental utilizado é o que envolve a indução da diarreia com óleo de rícino. Conforme Sousa e Colaboradores (2016), o óleo rícino ou óleo de mamona, é um laxante eficaz, amplamente utilizado para estudar os sintomas associados à diarreia e aos distúrbios relacionados à motilidade intestinal. De acordo com Bezerra (2018), a diarreia causada pelo óleo rícino ocorre devido à formação do ácido ricinoleico no lúmen intestinal, levando a alterações no intestino, como a constrição da musculatura lisa, contribuindo para a gravidade da diarreia. Segundo Sousa (2016), o óleo rícino é hidrolisado pela enzima lipase transformando-se no ácido ricinoleico, sendo o indutor da diarreia. Além disso, o óleo rícino o promovedor da síntese e da liberação de prostaglandinas, do fator de ativação das plaquetas e do óxido nítrico, associando com a secreção de eletrólitos no intestino delgado e à estimulação da motilidade do músculo liso, contribuindo para o efeito laxante. Semelhante ao estudo de Leódido (2017), o ácido ricinoleico, irritante da mucosa intestinal, promove também o efeito laxativo por meio da liberação de histaminas. Ademais, o óleo de rícino induz mudanças na permeabilidade da membrana da mucosa intestinal e aumenta a motilidade intestinal, que são justamente os três parâmetros que se encontram alterados na fisiopatologia das doenças diarreicas. 
Os estudos avaliados mostraram que o tratamento com polissacarídeos conseguiu regredir o número de episódios de diarreia, atuando em parâmetros que envolvem a redução da secreção de fluidos pelos enterócitos, aumento da reabsorção e diminuição da motilidade intestinal. Segundo Bezerra (2018), o tratamento com a alga Gracilaria cervicornis apresentou diminuição significativa da frequência de defecação e do número total de fezes diarreicas em todas as doses testadas. Além disso, reduziu significativamente o volume intestinal, diminuindo a quantidade do conteúdo intestinal. Conforme o estudo de Leódido (2017), o pré-tratamento com alga Graciliaria caudata, mostrou redução significativa na massa fecal total. A alga $G$. caudata reduziu a perda de fluído e inibiu a diarreia, porém não reduziu o volume de conteúdo intestinal, semelhante ao estudo de Costa (2016), onde neste, porém, houve redução do volume de conteúdo intestinal. De acordo com Sousa (2016), a administração de PLS da alga H. musciformis inibiu o acúmulo de fluido intestinal e proporcionou melhor efeito antidiarreico.

Resultados semelhantes também foram encontrados em estudos com polissacarídeos extraídos de espécies vegetais, tais como: Anacardium occidentale (Araújo, et al., 2015) e Anadenanthera colubrina (Araújo et al., 2020). Através da análise destes estudos pode-se observar que os resultados obtidos nos ensaios biológicos sugerem que a atividade antidiarreica dos polissacarídeos se deve à sua capacidade de alterar os parâmetros fecais, inibir o acúmulo de fluidos intestinais, estimulando a atividade de $\mathrm{N}+/ \mathrm{K}+-\mathrm{ATPase}$ nos enterócitos e reduzir a motilidade gastrointestinal, possivelmente por vias anticolinérgicas, opióides e/ou através do bloqueio físico do influxo extracelular de íons na mucosa, consequentemente, inibindo as contrações do músculo liso intestinal.

\section{Conclusão}

Os polissacarídeos são polímeros heterogêneos com grande importância biotecnológica, estando presentes em tecidos extracelulares de uma vastidão de organismos vivos, dentre estes, plantas superiores e algas. Os DGI possuem alta prevalência a nível mundial e são caracterizados por manifestações clínicas que acometem os tecidos e órgãos do trato gastrintestinal. As opções terapêuticas disponíveis para o tratamento desses distúrbios estão associadas a efeitos colaterais de gravidade variável, podendo estender-se desde leves a graves. Reconhecidos por suas interações eletrostáticas com proteínas específicas e pelo grande número de atividades biológicas, incluindo propriedades anti-inflamatória, antioxidante, gastroprotetora e antidiarreica, os polissacarídeos naturais surgem como uma alternativa interessante para o desenvolvimento de terapias inovadoras para DGI. No entanto, algumas questões permanecem sem solução nos estudos investigados, portanto, trabalhos futuros e metodologias refinadas são necessários para estabelecer a real eficácia dos polissacarídeos, tais como: 1) a estrutura precisa e o peso molecular dos polissacarídeos devem ser determinados, 2) a relação estrutura-atividade de polissacarídeos no tratamento das DGI precisa ser melhor investigada e 3) mais investigações de polissacarídeos por meio de experimentos clínicos são necessários para determinar a segurança e eficácia desses produtos naturais.

\section{Referências}

Andrade, K., de Carvalho, C. W., \& Takeiti, C. Y. (2013). Goma de cajueiro (Anacardium occidentale): avaliação das modificações químicas e físicas por extrusão termoplástica. Polímeros, 23, 667-671.

Araújo, T. M. E. D., Dantas, J. M., Carvalho, C. E. F., \& Costa, M. A. D. O. (2010). Surto de diarreia por rotavírus no município de Bom Jesus (PI). Ciência \& Saúde Coletiva, 15, 1039-1046.

Araújo, T. S., Costa, D. S., Sousa, N. A., Souza, L. K., de Araújo, S., Oliveira, A. P., ... \& Medeiros, J. V. R. (2015). Antidiarrheal activity of cashew GUM, a complex heteropolysaccharide extracted from exudate of Anacardium occidentale L. in rodents. Journal of ethnopharmacology, $174,299-307$.

Araújo, T. S., de Oliveira, T. M., de Sousa, N. A., Souza, L. K., Sousa, F., de Oliveira, A. P., ... \& Medeiros, J. V. R. (2020). Biopolymer extracted from anadenanthera colubrina (Red angico gum) exerts therapeutic potential in mice: antidiarrheal activity and safety assessment. Pharmaceuticals, $13(1), 17$.

Avres-Ostrock, L. M. (2014). Estudos populacionais em Gracilaria birdiae e G. caudata (Gracilariales, Rhodophyta): aspectos fenológicos, fisiológicos e moleculares (Doctoral dissertation, Universidade de São Paulo). 
Barbosa, S., Santos, A. C. A., Lima, A. R., Melo, S., Frazão, C. D. S., \& Cherpak, G. L. (2010). Comparação da eficácia da aroeira oral (Schinus terebinthifolius Raddi) com omeprazol em pacientes com gastrite e sintomas dispépticos: estudo randomizado e duplo-cego. GED gastroenterol. endosc. dig, 29(4), 118-125

Batista, J. A., de Aguiar Magalhães, D., Sousa, S. G., dos Santos Ferreira, J., Pereira, C. M. C., do Nascimento Lima, J. V., ... \& dos Reis Barbosa, A. L. (2020). Polysaccharides derived from Morinda citrifolia Linn reduce inflammatory markers during experimental colitis. Journal of ethnopharmacology, 248, 112303.

Batista, N., Regis, C., Silva, I., \& Batista, H. (2016). A abordagem qualitativa na pesquisa em educação médica. CIAIQ2016, 2.

Bezerra, F. F., Lima, G. C., de Sousa, N. A., de Sousa, W. M., Costa, L. E. C., da Costa, D. S., ... \& Freitas, A. L. P. (2018). Antidiarrheal activity of a novel sulfated polysaccharide from the red seaweed Gracilaria cervicornis. Journal of ethnopharmacology, 224, 27-35.

Bighetti, A. É., Antônio, M. A., \& de Carvalho, J. E. (2002). Regulação e modulação da secreção gástrica. Revista de Ciências Médicas, 11(1).

Bingana, R. D. (2020). Proteção tópica in vitro da mucosa esofágica de pacientes com doença do refluxo gastroesofágico usando a "goma do angico", um biopolímero de Anadenanthera colubrina.

Brasil, F. I. (2013). Os alginatos e suas múltiplas aplicações. Revista Fib, (26), 34-38

Brito, T. V., Barros, F. C., Silva, R. O., Júnior, G. J. D., Júnior, J. S. C., Franco, Á. X., ... \& Barbosa, A. L. R. (2016). Sulfated polysaccharide from the marine algae Hypnea musciformis inhibits TNBS-induced intestinal damage in rats. Carbohydrate polymers, 151, 957-964.

Brito, T. V., Neto, J. P., Prudêncio, R. S., Batista, J. A., Júnior, J. S., Silva, R. O., ... \& Barbosa, A. L. (2014). Sulfated-polysaccharide fraction extracted from red algae Gracilaria birdiae ameliorates trinitrobenzenesulfonic acid-induced colitis in rats. Journal of Pharmacy and Pharmacology, 66(8), 1161-1170.

Carneiro, J. G., Holanda, T. D. B. L., Quinderé, A. L. G., Frota, A. F., Soares, V. V. M., Sousa, R. S. D., ... \& Benevides, N. M. B. (2018). Gastroprotective effects of sulphated polysaccharides from the alga Caulerpa mexicana reducing ethanol-induced gastric damage. Pharmaceuticals, 11 (1), 6.

Carvalho, N. S., Silva, M. M., Silva, R. O., Nicolau, L. A., Sousa, F. B. M., Damasceno, S. R., ... \& Medeiros, J. V. R. (2015). Gastroprotective properties of cashew gum, a complex heteropolysaccharide of Anacardium occidentale, in naproxen-induced gastrointestinal damage in rats. Drug Development Research, 76(3), 143-151.

Cheng, F., Zhang, Y., Li, Q., Zeng, F., \& Wang, K. (2020). Inhibition of dextran sodium sulfate-induced experimental colitis in mice by Angelica Sinensis polysaccharide. Journal of medicinal food, 23(6), 584-592.

Costa, D. S., Araújo, T. S., Sousa, N. A., Souza, L. K., Pacífico, D. M., Sousa, F. B. M., ... \& Medeiros, J. V. R. (2016). Sulphated polysaccharide isolated from the seaweed Gracilaria caudata exerts an antidiarrhoeal effect in rodents. Basic \& clinical pharmacology \& toxicology, 118(6), $440-448$.

COSTA, D.S. (2016). Atividade antidiarreica de uma fração polissacarídica sulfatada extraída de Gracilaria caudata (j agardh) em roedores. Dissertação (Mestrado em Farmacologia). 105f. (Universidade Federal do Piauí, Teresina-PI).

Cui, L., Guan, X., Ding, W., Luo, Y., Wang, W., Bu, W., ... \& Feng, L. (2021). Scutellaria baicalensis Georgi polysaccharide ameliorates DSS-induced ulcerative colitis by improving intestinal barrier function and modulating gut microbiota. International Journal of Biological Macromolecules, 166, 10351045 .

Cui, L., Wang, W., Luo, Y., Ning, Q., Xia, Z., Chen, J., ... \& Jia, X. (2019). Polysaccharide from Scutellaria baicalensis Georgi ameliorates colitis via suppressing NF- $\mathrm{B}$ signaling and NLRP3 inflammasome activation. International journal of biological macromolecules, 132, $393-405$.

Cunha, P. L. R. D., Paula, R. C. M. D., \& Feitosa, J. (2009). Polissacarídeos da biodiversidade brasileira: uma oportunidade de transformar conhecimento em valor econômico. Química Nova, 32(3), 649-660.

Damasceno, S. R., Rodrigues, J. C., Silva, R. O., Nicolau, L. A., Chaves, L. S., Freitas, A. L., ... \& Medeiros, J. V. R. (2013). Role of the NO/K ATP pathway in the protective effect of a sulfated-polysaccharide fraction from the algae Hypnea musciformis against ethanol-induced gastric damage in mice. Revista Brasileira de Farmacognosia, 23, 320-328.

Ddine, L. C., Ddine, C. C., Rodrigues, C. C. R., Kirsten, V. R., \& Colpo, E. (2012). Fatores associados com a gastrite crônica em pacientes com presença ou ausência do Helicobacter pylori. ABCD. Arquivos Brasileiros de Cirurgia Digestiva (São Paulo), 25, 96-100.

de Araújo, S., Sousa, I. J. O., Gonçalves, R. L. G., de Sousa França, A. R., dos Santos Negreiros, P., da Silva Brito, A. K., ... \& de Sousa Lima, E. B. (2018). Aplicações Farmacológicas e Tecnológicas da Goma do Cajueiro (Anacardium Occidentale L.)-um Produto Obtido da Flora Brasileira. Revista GeintecGestao Inovacao E Tecnologias, 8(1), 4292-4305.

Dias, N., Santos, P., Pinto, M., Fernandes, C., Júnior, A., Souza, S., ... \& Alves, F. (2015). Análise de prontuários de pacientes com gastrite em um hospital na região oeste ii do estado de Goiás. Revista Eletrônica Faculdade Montes Belos, 8(1).

dos Santos Silva, M. M., de Moura Neto, L. G., Soares, D. J., \& do Nascimento, A. D. P. (2018). Utilização da farinha de alfarroba (Ceratonia siliqua) para elaboração de iogurte. CIENTEC-Revista de Ciência, Tecnologia e Humanidades do IFPE, 9(3).

Dutra, N. L. S., de Brito, T. V., de Aguiar Magalhães, D., Sousa, S. G., Batista, J. A., Pereira, C. M. C., ... \& dos Reis Barbosa, A. L. (2021). Sulfated polysaccharide extracted from seaweed Gracilaria caudata attenuates acetic acid-induced ulcerative colitis. Food Hydrocolloids, 111 , 106221.

El Sayed, M., Ghareeb, D., Sarhan, E., \& Khalil, A. (2011). Therapeutic bio-screening of the bioactive ingredients of Berberis vulgaris. Functional Plant Science and Biotechnology, 5(1), 63-68. 
Figueiredo, A. A., Sales, T. M., Nicolau, L. A., Nunes, A. A., Costa-Filho, H. B., Moreira, R. L., ... \& Souza, M. H. (2020). Laryngeal Mucosa Alterations in Mice Model of Gastroesophageal Reflux: Effects of Topical Protection. The Laryngoscope, 130(12), E889-E895.

Fonseca, J. A. (2016). Aplicação de algas na indústria alimentar e farmacêutica (Doctoral dissertation).

França, E. B., Lansky, S., Rego, M. A. S., Malta, D. C., França, J. S., Teixeira, R., ... \& Vasconcelos, A. M. N. (2017). Principais causas da mortalidade na infância no Brasil, em 1990 e 2015: estimativas do estudo de Carga Global de Doença. Revista Brasileira de Epidemiologia, $20,46-60$.

Galvão, M. C. B., \& Ricarte, I. L. M. (2019). Revisão sistemática da literatura: conceituação, produção e publicação. Logeion: Filosofia da informação, 6(1), 57-73.

Garcia-Cruz, C. H., Foggetti, U., \& Silva, A. N. D. (2008). Alginato bacteriano: aspectos tecnológicos, características e produção. Química nova, 31(7), 18001806.

Georgieva, M., Manios, Y., Rasheva, N., Pancheva, R., Dimitrova, E., \& Schaafsma, A. (2016). Effects of carob-bean gum thickened formulas on infants' reflux and tolerance indices. World journal of clinical pediatrics, 5(1), 118.

Henry, M. A. C. D. A. (2014). Diagnóstico e tratamento da doença do refluxo gastroesofágico. ABCD. Arquivos Brasileiros de Cirurgia Digestiva (São Paulo), 27, 210-215.

Heringer, T. O., Prestes, T. R. R., Bottega F. C., Silva, A. A. S., \& Pedroso, E. R. P. (2018). Caso 26. Rev Med Minas Gerais $2018 ; 28:$ e-1995.

Kakagia, D., Papalois, A., Lambropoulou, M., Papachristou, F., Trypsiannis, G., Anagnostopoulos, C., ... \& Tsaroucha, A. (2020). The Use of Pistacia Lentiscus Chia Resin versus Omeprazole in Protecting Male Rats Peptic Mucosa against Cold Restraint Stress. The Journal of Critical Care Medicine, 6(2), 100 .

Leódido, A. C. M., Costa, L. E., Araújo, T. S., Costa, D. S., Sousa, N. A., Souza, L. K., ... \& Medeiros, J. V. R. (2017). Anti-diarrhoeal therapeutic potential and safety assessment of sulphated polysaccharide fraction from Gracilaria intermedia seaweed in mice. International journal of biological macromolecules, $97,34-45$.

Lucena, A. M., Souza, C. R., Jales, J. T., Guedes, P. M., De Miranda, G. E., De Moura, A., ... \& Souto, J. T. (2018). The bisindole alkaloid caulerpin, from seaweeds of the genus Caulerpa, attenuated colon damage in murine colitis model. Marine drugs, 16(9), 318.

Lucetti, L. T. (2014). Ações de doadores de óxido nítrico ou de sulfeto de hidrogênio (H2S) e possíveis interações entre os dois sistemas nas funções gástricas.

Lv, J., Zhang, Y., Tian, Z., Liu, F., Shi, Y., Liu, Y., \& Xia, P. (2017). Astragalus polysaccharides protect against dextran sulfate sodium-induced colitis by inhibiting NF- $\kappa \mathrm{B}$ activation. International journal of biological macromolecules, 98, 723-729.

Maria-Ferreira, D., Nascimento, A. M., Cipriani, T. R., Santana-Filho, A. P., da Silva Watanabe, P., Sant, D. D. M. G., ... \& Baggio, C. H. (2018). Rhamnogalacturonan, a chemically-defined polysaccharide, improves intestinal barrier function in DSS-induced colitis in mice and human Caco-2 cells. Scientific reports, $8(1), 1-14$.

Monturil, H. P. H. R., de Brito, T. V., da Cruz Junior, J. S., Júnior, G. J. D., de Aguiar Magalhães, D., Sousa, S. G., ... \& Barbosa, A. L. D. R. (2020). Sulfated polysaccharide from Digenea simplex decreases intestinal inflammation in rats. Revista Brasileira de Farmacognosia, 30, 388-396.

Nicolau, L. A., Batista-Lima, F. J., Santana, A. P., Sales, T. M., Carmo-Neto, J. P., Freitas, G. B., ... \& Souza, M. H. (2019). Cashew gum, a biopolymer, topically protects oesophageal mucosa in non erosive reflux disease: A promising translational study. Carbohydrate polymers, $226,115205$.

Niu, W., Chen, X., Xu, R., Dong, H., Yang, F., Wang, Y., ... \& Ju, J. (2021). Polysaccharides from natural resources exhibit great potential in the treatment of ulcerative colitis: a review. Carbohydrate polymers, $254,117189$.

Oliveira, G. L. A., de Stefani Marquez, D., de Jesus Fukui, M., \& Júnior, M. E. M. (2012). Fatores associados à gastrite crônica na infecção por Helicobacter Pylori. Arquivos Brasileiros de Cirurgia Digestiva (São Paulo) 25, 96-100.

PamphilE, J. A., Costa, A. T., Rosseto, P., Polonio, J. C., Pereira, J. O., \& Azevedo, J. L. (2017). aplicações biotecnológicas de metabólitos secundários extraídos de fungos endofíticos: o caso do Colletotrichum sp. REVISTA UNINGÁ, 53(1).

Pereira, L. B., Gonçalves, A. M. R. F., Fernandes, C. S. E., Fontanella, A. T., Francisco, P. M. S. B., Mengue, S. S., ... \& Costa, K. S. (2020). Utilização de medicamentos para distúrbios gastrintestinais: evidências da Pesquisa Nacional sobre Acesso, Utilização e Promoção do Uso Racional de Medicamentos. Einstein (São Paulo), 18.

Rodriguez-Canales, M., Jimenez-Rivas, R., Canales-Martinez, M. M., Garcia-Lopez, A. J., Rivera-Yañez, N., Nieto-Yañez, O., ... \& Rodriguez-Monroy, M. A. (2016). Protective effect of Amphipterygium adstringens extract on dextran sulphate sodium-induced ulcerative colitis in mice. Mediators of inflammation, 2016.

Romãozinho, J. M. (2014). «Bolsa de ácido» e suas implicações na patogenia e na terapêutica farmacológica da doença do refluxo gastroesofágico. Jornal Português de Gastrenterologia, 21(1), 3-4.

Rosenthal, R., Luettig, J., Hering, N., Krug, S., Albrecht, U., Fromm, M., \& Schulzke, J. D. (2017). Myrrh exerts barrier-stabilising and-protective effects in HT-29/B6 and Caco-2 intestinal epithelial cells. International journal of colorectal disease, 32(5).

Sales, T. M. A. L., Nicolau, L. A. D., Rodrigues, R. L. M., Nascimento, R. R., Paula, S. M., da Costa-Filho, H. B., ... \& Souza, M. H. L. P. (2020). Polysaccharide from Gracilaria caudata protects the human esophageal mucosal barrier: A differential topical effect and structural dependence. International journal of biological macromolecules, 150, 354-361. 
Silva, R. O., Santana, A. P. M., Carvalho, N. S., Bezerra, T. S., Oliveira, C. B., Damasceno, S. R., ... \& Medeiros, J. V. R. (2012). A sulfated-polysaccharide fraction from seaweed Gracilaria birdiae prevents naproxen-induced gastrointestinal damage in rats. Marine drugs, 10(12), 2618-2633.

Silva, R. O., Santos, G. M. P. D., Nicolau, L. A. D., Lucetti, L. T., Santana, A. P. M., Chaves, L. D. S., ... \& Medeiros, J. V. R. (2011). Sulfatedpolysaccharide fraction from red algae Gracilaria caudata protects mice gut against ethanol-induced damage. Marine drugs, 9(11), 2188-2200.

Silva, T. O. L. D. A., Gomes, K. C. F., Sales Filho, R., \& Costa, H. F. (2018). Análise histológica da mucosa gástrica saudável e doente com gastrite crônica ou doença ulcerosa péptica. Revista de Ciências da Saúde Nova Esperança, 16(3), 43-50.

Sousa, N. A., Barros, F. C. N., Araújo, T. S., Costa, D. S., Souza, L. K. M., Sousa, F. B. M., ... \& Medeiros, J. V. R. (2016). The efficacy of a sulphated polysaccharide fraction from Hypnea musciformis against diarrhea in rodents. International journal of biological macromolecules, $86,865-875$.

Sousa, W. M., Silva, R. O., Bezerra, F. F., Bingana, R. D., Barros, F. C. N., Costa, L. E., ... \& Freitas, A. L. P. (2016). Sulfated polysaccharide fraction from marine algae Solieria filiformis: Structural characterization, gastroprotective and antioxidant effects. Carbohydrate polymers, 152, $140-148$.

Su, L., Mao, C., Wang, X., Li, L., Tong, H., Mao, J., ... \& Yan, G. (2020). The anti-colitis effect of Schisandra chinensis polysaccharide is associated with the regulation of the composition and metabolism of gut microbiota. Frontiers in cellular and infection microbiology, 10.

Takagi, T., Naito, Y., Higashimura, Y., Ushiroda, C., Mizushima, K., Ohashi, Y., ... \& Yoshikawa, T. (2016). Partially hydrolysed guar gum ameliorates murine intestinal inflammation in association with modulating luminal microbiota and SCFA. British Journal of Nutrition, 116(7), 1199-1205.

Tang, S., Liu, W., Zhao, Q., Li, K., Zhu, J., Yao, W., \& Gao, X. (2021). Combination of polysaccharides from Astragalus membranaceus and Codonopsis pilosula ameliorated mice colitis and underlying mechanisms. Journal of Ethnopharmacology, 264, 113280.

Torres, P. B. (2017). Caracterização química e atividades biológicas de algumas espécies nativas de Gracilaria de importância econômica (Doctoral dissertation, Universidade de São Paulo).

Vasconcelos, A. G., de Araújo, K. V., \& Santana, L. D. A. B. (2015). Polissacarídeos extraídos de algas marinhas e suas aplicações biotecnológicas: uma revisão. Revista Brasileira de Inovação Tecnológica em Saúde-ISSN: 2236-1103.

Wang, Y., Ji, X., Yan, M., Chen, X., Kang, M., Teng, L., ... \& Deng, C. (2019). Protective effect and mechanism of polysaccharide from Dictyophora indusiata on dextran sodium sulfate-induced colitis in C57BL/6 mice. International journal of biological macromolecules, 140, 973-984.

Zhang, R., Yuan, S., Ye, J., Wang, X., Zhang, X., Shen, J., ... \& Liao, W. (2020). Polysaccharide from flammuliana velutipes improves colitis via regulation of colonic microbial dysbiosis and inflammatory responses. International journal of biological macromolecules, 149, 1252-1261.

Zheng, B., Ying, M., Xie, J., Chen, Y., Wang, Y., Ding, X., ... \& Yu, Q. (2020). A Ganoderma atrum polysaccharide alleviated DSS-induced ulcerative colitis by protecting the apoptosis/autophagy-regulated physical barrier and the DC-related immune barrier. Food \& Function, 11(12), 10690-10699. 